\title{
DIMENSIONES DEL PRINCIPIO DE SOLIDARIDAD: UN ESTUDIO FILOSÓFICO
}

\author{
DIMENSIONS OF THE PRINCIPLE OF SOLIDARITY: \\ A PHILOSOPHICAL STUDY
}

\begin{abstract}
Luis EMilio Rojas A.*
RESUMEN: A partir de una crítica a la definición originaria de los deberes positivos, por su tendencia a confundirlos con la categoría de la solidaridad, el trabajo revisa luego una serie de planteamientos filosóficos con el objeto de proponer una diferenciación al interior del principio de solidaridad. Esta indagación, que al mismo tiempo parte de la premisa de una asimetría entre libertad y solidaridad en un Estado liberal de Derecho, permitiría plantear una diferencia entre, por un lado, el deber general de auxilio y, por otro, los deberes de solidaridad del ciudadano en relación con el Estado.
\end{abstract}

Palabras clave: libertad, deberes positivos, principio de solidaridad.

ABSTRACT: from a critique of the original definition of positive duties, by their tendency to be confused with the category of solidarity, the essay reviews a series of philosophical approaches in order to propose a differentiation internal to the principle of solidarity. This inquiry, which starts at the same time from the premise of an asymmetry between freedom and solidarity in a liberal rule of law, would make it possible to differentiate between, on the one hand, the general duty of rescue and, on the other, the duties of solidarity of the citizen in relation to the state.

Key words: freedom, general duty of rescue, principle of solidarity.

\section{EL PROBLEMA DE LA IDENTIDAD CONCEPTUAL ENTRE DEBERES POSITIVOS Y SOLIDARIDAD}

En su formidable manual de parte general, Jakobs introduce la ya muy conocida distinción entre competencia por organización y competencia por institución, que sirve para explicar el fundamento mismo de la responsabilidad penal. De este modo, se aparta frontalmente de la tradición dogmática previa que todavía le asignaba un valor constitutivo a la diferencia entre acción y omisión, tradición que se remonta al menos a la obra clásica de Radbruch sobre el concepto de acción ${ }^{1}$.

\footnotetext{
Profesor de Derecho Penal, Universidad Alberto Hurtado, Chile. Email: lurojas@uahurtado.cl. Trabajo ulterior del proyecto Fondecyt No 1150178 sobre "Líneas básicas de una dogmática de los delitos propios de omisión: una aproximación a los deberes de solidaridad y al significado de su infracción”, cuyo investigador responsable fue el autor; una versión preliminar del trabajo fue sometida a discusión en el marco del correspondiente workshop que tuvo lugar el 21 y 22 de marzo de 2018; agradecimientos al ayudante de investigación Mg. Claudio Quintana.

1 RADBRUCH (1967) p. 75, define hecho como "un movimiento corporal vinculado causalmente a un resultado"; bajo este concepto de hecho punible, define luego la omisión a partir de la negación de una acción deter-
} 
Lo determinante, según Jakobs, ya no es la diferencia netamente descriptiva entre acción y omisión, sino que el diverso fundamento de la responsabilidad. Así, observa que junto a la competencia fundada en la propia organización, existen deberes cuyo contenido radica en el "cuidado solidario de un bien" asegurado especial e institucionalmente. En esta clase de deberes, dice, la relación entre el sujeto y el bien se encuentra determinada no solamente de forma negativa, sino que positivamente mediante el status del autor en relación con el bien².

Mucho más adelante, al tematizar esta clase de deberes fundada en la competencia institucional en el marco de los delitos impropios de omisión, Jakobs señala que aquí se trata de "la unión de ámbitos de vida, idealmente de un mundo a construir parcialmente

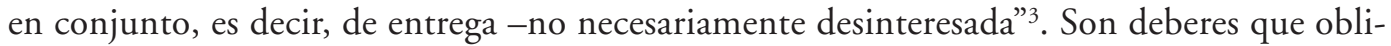
gan al detrimento propio - v.gr.: al sacrificio, "esto es, a la garantía de solidaridad" 4 .

Estos deberes, a su vez, se diferencian de las normas sobre omisión de socorro y omisión de denuncia -§§ 323 c, 138 y s., respectivamente, del Código penal alemán (en adelante, StGB), donde se penaliza la "infracción de la solidaridad mínima general ante el peligro para bienes sumamente relevantes" .

Esta diferenciación entre competencia por organización y por institución es sin duda muy sugerente e iluminadora, en tanto otorga un sustento material a la distinción usual entre deberes negativos y deberes positivos. Es más, se puede decir que constituye todo un hito en la ciencia moderna del Derecho penal. No obstante, y sin perjuicio de reconocerlo explícitamente así, la definición ofrecida de los deberes positivos contiene una referencia doblemente equívoca a la solidaridad, cuya huella aún puede perseguirse en la discusión reciente ${ }^{6}$.

En primer término, el concepto ofrecido de los deberes institucionales es equívoco, puesto que tiende a igualar el contenido de estos deberes con la categoría de la solidaridad. Esta se vuelve idéntica con el carácter positivo del deber, cuyo alcance radicaría en mejorar el status quo del otro. Una obligación con este alcance, empero, pertenece más bien al ámbito de la moral y, por ende, en principio se restringe a este ${ }^{7}$.

minada y luego extrae la consecuencia de que la acción se comporta en relación con la omisión como posición (acción) y negación (omisión), a y non-a (pp. 140 y ss.).

2 JAKOBS (1993) cap. I, Apdo. 7 núm. marg. 70.

3 JAKоBS (1993) cap. VI, Apdo. 29 núm. marg. 58; enseguida aclara que, en la relación entre padres e hijos, se trata de un estándar mínimo, pues no se encuentra garantizada jurídico-penalmente la "entrega óptima" (núm. marg. 60), precisión que vale con mayor razón en el ámbito de la relación matrimonial (núm. marg. 63).

${ }^{4}$ JaKobs (1993) cap. VI, Apdo. 28 núm. marg. 15 (destacado agregado); un tiempo antes, más en general respecto de los deberes de garante, ya SAMSON (1971) p. 595: "las prohibiciones derivan así del pensamiento individualista, los mandatos determinan el alcance del deber a la solidaridad recíproca", luego, "infringe una prohibición quien realiza una intromisión perjudicial, infringe un mandato quien no rinde una prestación mejoradora"; postula un contraste similar entre prohibiciones y mandatos NovOA (1984) pp. 33 y ss.

5 JAKовS (1993) cap. VI, Apdo. 28 núm. marg. 11.

${ }^{6}$ Véase la discusión entre Robles (2013) pp. 5 y ss., y SÁnchez-Vera (1999a) pp. 102 y ss.; SÁnCHEZ-VERA (1999b) pp. 361 y ss.; cfr. NAVAS (2018) p. 59 y s., quien además ofrece un panorama de los deberes positivos generales y especiales reconocidos en la parte especial de la legislación penal, pp. 63 y ss.

7 En este sentido, KANT (1978) p. 551 y s. (1 a ed. 1797 A 66, 67), trata los deberes positivos a propósito de los debes contra sí mismo - "hazte más completo de aquello que la naturaleza te dio", en el acápite sobre doctrina elemental de la ética; Hegel (2010) § 35 p. 90 y s., en el capítulo sobre doctrina de los deberes o la moral, explica que los preceptos de la moral, en contraste con el mandato jurídico, ordenan proporcionar algo positivo al otro. 
Probablemente dicha igualación sea la que explique, al menos en parte, la actitud reticente en la doctrina ante el reconocimiento y la inclusión de esta clase de deberes entre las normas del Derecho penal, las que, por el contrario, se arguye, deberían acotarse a la protección de la libertad externa mediante la imposición solamente de deberes negativos. Esta crítica se traduce, entonces, en una actitud escéptica e incluso de rechazo frente al auténtico proceso de moralización del Derecho penal que implicaría dicho reconocimiento ${ }^{8}$.

$\mathrm{Y}$, en efecto, los deberes institucionales son positivos porque su contenido no se reduce a la obligación de no perjudicar los derechos de otro, sino que incluye además una prestación de mejoramiento del status quo de este. Este contenido del deber institucional resulta patente en el marco de la relación filial. Pero, justamente en la medida en que aquí se trata de deberes especiales -Jakobs dice: asegurados institucional y especialmente- y que, correlativamente, el favorecido tiene el derecho a exigir del sujeto obligado su cumplimiento, resulta bastante inadecuado seguir hablando en este contexto de "solidaridad entre personas".

En segundo lugar, el deber general de auxilio subyacente, por ejemplo, al tipo de omisión de socorro, también se califica de positivo en el sentido antes dicho9. Y esta calificación, enseguida, lo vuelve objeto de la misma crítica dirigida a los deberes institucionales.

Ciertamente, el deber general de auxilio en una situación de peligro, cuyo contenido se agota en la "solidaridad mínima" -v.gr.: art. 494 No 14 del Código penal (en adelante, $\mathrm{CP}$ ), también es positivo en el sentido de que obliga a una prestación en favor del otro que se encuentra en dicha situación ${ }^{10}$. Sin embargo, el alcance de este deber se reduce a prestar una colaboración para superar dicha situación de peligro, de modo que resulta algo excesivo suponer que obliga al mejoramiento del status quo del otro.

\footnotetext{
8 Contra la juridificación de los deberes de solidaridad -incluyendo entre estos al deber general de socorro y a los deberes positivos especiales- Seelmann (1991) pp. 299 y ss., Seelmann (2013) pp. 35 y ss., 44 y ss., opone tres argumentos: primero, el de libertad, según el cual los deberes en cuestión se dirigen al contenido de la voluntad y a las necesidades individuales del otro, diferenciándose en esto de los propiamente jurídicos -que, en cambio, se sustentan en un vínculo recíprocamente referido solamente a la capacidad de formación de la voluntad-; segundo, el argumento de generalización, en orden a evidenciar que el "altruismo" no puede generalizarse sin promover al mismo tiempo la dependencia incluso del propio sujeto capaz de prestar la ayuda respecto de esta, en otras palabras, su generalización conduce a la disolución del propio "altruismo"; y, tercero, el argumento del ámbito del juego, según el cual esa clase de deberes se encuentra infradeterminada, pues su cumplimiento exige antes determinar la necesidad de la ayuda, además porque hay cada vez más necesitados y, por ende, el sujeto capaz de prestar la ayuda necesariamente debe elegir al beneficiado por la misma, de todo lo cual se sigue, en fin, que es prácticamente imposible constatar la infracción de tal clase de deberes; este último argumento proviene ya de PHiLIPps (1974) pp. 15 y ss., 21 y ss., quien subraya el contraste entre prohibiciones y mandatos, en el sentido de que las primeras fijan límites, mientras que los segundos establecen un fin, cuyo logro es siempre dependiente de la determinación temporal del momento de su cumplimiento; los mandatos suponen un requerimiento de lograr un objetivo al interior de un ámbito de acción hasta un momento temporal determinado (p. 58); el cumplimiento del mandato es estructuralmente dependiente de la situación espaciotemporal, donde el destinatario puede elegir uno u otro curso de acción posible, pero siempre al menos uno que conduzca al logro del fin (p. 66 y s.).

9 Crítico Kargl (1994) pp. 249 y ss., quien califica al tipo general de omisión de socorro como un paradigma de la juridificación de deberes morales y ético-sociales de conducta, en sus palabras, un ejemplo de la moral interna del Derecho.

10 Así Mieth (2012) p. 96 nota 26, sugiere hablar de deberes de prestación en lugar de deberes de acción; quizás el equívoco surge del carácter supuestamente "positivo" de estos deberes.
} 
Además, y a diferencia de lo que ocurre con los deberes institucionales, aquí no resulta para nada evidente hablar de un derecho del otro a exigir correlativamente el cumplimiento de dicho deber general. Detrás de la crítica antes reseñada de moralización del Derecho penal que implicaría su reconocimiento formal se encuentra, en el fondo, un cuestionamiento de la existencia de este derecho correlativo. Se requiere, entonces, un considerable esfuerzo de fundamentación filosófico-jurídica para fundar tal derecho de la víctima en la situación de peligro.

Pues bien, el presente trabajo ofrece un estudio de orientación predominantemente filosófica con el doble propósito de asentar, por un lado, la diferencia entre los deberes positivos especiales e institucionales y el principio de solidaridad y de explorar, por el otro, una fundamentación diferenciada de este último, que permita así distinguir entre el deber general de auxilio y lo que puede llamarse "solidaridad ciudadano-estatal" como sustento del Estado social.

En este sentido, una concepción liberal del Derecho penal tendría que partir no solo de una complementariedad, sino que antes bien de una asimetría entre libertad y solidaridad -i.e.: entre autonomía y solidaridad ${ }^{11}$. Si el Estado social supone una evolución del Estado liberal de Derecho, es decir, se traduce en un estadio más avanzado de este, entonces dicha asimetría no puede desdibujarse por el desarrollo moderno de la seguridad social y su infraestructura. La conservación de esa asimetría permitiría desarticular la igualación antes mencionada entre el carácter positivo de los deberes institucionales y la idea de solidaridad. Podría disolverse así la conceptualización equívoca antes denunciada, i.e. la que surge del concepto ofrecido por Jakobs de esta clase de deberes positivos -especiales.

Ante la segunda conceptualización equívoca, es decir, la que surge de identificar sin más el carácter positivo ahora del deber general de auxilio con la categoría de la solidaridad, cabe poner de relieve la diferencia entre el contenido de tal deber y el deber de beneficencia, cuyo origen se reducía históricamente al ámbito de la moral, pero que con el desarrollo aún incipiente del Estado de bienestar alcanza su formalización y positivización, convirtiéndose así en Derecho -social o de la seguridad social. Si se considera esa diferencia, entonces es plausible sostener que, bajo la categoría de la solidaridad, el deber de auxilio ocupa una posición disímil en relación con la idea de Estado social y los deberes del ciudadano que este supone. Se trata de componentes diversos al interior del principio de solidaridad.

\section{OTRA VEZ: ACERCA DE LA RELACIÓN ENTRE LIBERTADY SOLIDARIDAD}

Siempre es útil indagar en las raíces históricas de un concepto. Por cierto, también es posible emprender esta tarea con la idea de solidaridad y retroceder así varios siglos ${ }^{12}$. No

\footnotetext{
11 Wilenmann (2014) pp. 124 y ss., sostiene que no existe una oposición entre autonomía formal y solidaridad, sino que, al contrario, la solidaridad es parte del concepto de la libertad jurídica, pues ella completa o complementa la libertad configurada por la autonomía formal: en este sentido, también KüHNBACH (2007) pp. 27 y s., 72.

12 Así lo hace RenZiKowski (2013) pp. 16 y ss.; también SeELmann (2013) pp. 38 y ss.; síntesis en VAN WeEZeL (2018) pp. 1109 y ss.
} 
obstante, por ahora interesa solamente volver a revisar el nexo entre libertad y solidaridad en el contexto originario del Estado de Derecho.

Obviamente, dicho nexo puede tematizarse así solo si se tienen presentes ambos elementos del mismo, a saber, la libertad en su relación con la solidaridad. Este segundo eslabón, empero, si ya existía en una forma primigenia -v.gr.: bajo la idea de "fraternidad"13, fue prontamente olvidado por el necesario esfuerzo dedicado a la justificación y legitimación del Estado de Derecho ${ }^{14}$. La concentración en el desarrollo de la idea general de libertad opacó tempranamente al otro componente de la relación.

\subsection{Regreso al origen: Kant, Hegel y el reconocimiento del Conflicto entre NECESIDAD Y DERECHO}

Ahora bien, y como suele ocurrir en general con las cuestiones de fundamento, resulta bien difícil volver al contexto originario del Estado de Derecho sin recurrir a Kant. Hasta donde se alcanza a ver, este filósofo no habla de "solidaridad" en su obra sobre "la metafísica de las costumbres". En cambio, por un lado, sí se refiere al "derecho de necesidad" en un anexo de la introducción a la doctrina del derecho y, por otro, tematiza el bienestar ("Wohlfahrt") y la benevolencia ("Wohlwollen") en la sección sobre doctrina de las virtudes.

Respecto del mentado "derecho de necesidad", Kant simplemente niega su existencia. En el caso de los náufragos que se encuentran aferrados a una tabla en la misma situación de peligro vital, formula el conocido dictum en los términos literales de que "la necesidad no tiene mandato" - traducida plásticamente como "la necesidad no conoce derecho" - y, en el mismo pasaje, que no puede existir una necesidad que vuelva jurídico -en el sentido de conforme a derecho- algo injusto: "Not hat kein Gebot (necessitas non habet legem)" 15 . Por ende, en tal situación extrema de necesidad, esta no funda ningún derecho ni tampoco un deber correlativo.

Por ejemplo, en ese caso, y supuesto que la tabla no le pertenece ni a A ni a B, A no tiene el derecho de arrojar a $\mathrm{B}$ de la tabla y este tampoco tiene el deber de tolerar la acción de A. La sola situación de necesidad, para Kant, jamás funda un derecho ni tampoco convierte en jurídica la realización de la acción por parte de A. Y lo mismo vale respecto de B.

En el otro lugar, donde aborda la teoría de las virtudes, Kant distingue entre el bienestar físico y el moral, junto con advertir que la benevolencia puede tornarse ilimitada. En este pasaje, observa que la felicidad ajena es un fin que al mismo tiempo es un deber, pues, dado que nuestro amor propio no puede separarse de la necesidad de ser amado -i.e. ayudado en casos de necesidad- por otros, nos convertimos así en un fin para otros. Y esta

\footnotetext{
13 Según Bourgeors (1902) p. 5 y s., 155 y s., la noción de solidaridad se vuelve usual en el discurso político recién a mitad del siglo XIX, por ende, no alcanzó a ser "republicana” en el contexto de la revolución francesa; agradecimientos al profesor Antonio Bascuñán por el descubrimiento de este bello escrito de filosofía política. La idea de fraternidad, en cambio, sí fue republicana y resurgió en el período revolucionario de 1848, cfr. GuZmán Dalbora (2016) pp. 66 y ss.

14 Depenheuer (1991/2009) p. 184 y s.

15 Kant (1978) introducción en la doctrina del derecho, AB 41, 42, p. 343 y s.
} 
máxima puede coexistir mediante su calificación como una ley general, por ende, mediante la voluntad también de convertir a los otros en fines para nosotros ${ }^{16}$.

Más adelante se refiere a la cuestión del amor al prójimo que concibe en los términos de un deber de hacer el bien a otro según nuestras capacidades, con o sin amor. Es decir, no supone el estado afectivo de amor, pues este no puede ser contenido de la voluntad y, por consiguiente, menos aún de una obligación -no se puede obligar a amar a otro ${ }^{17}$.

Finalmente, y todavía en ese contexto, Kant distingue la beneficencia ("Wohltätigkeit") de la benevolencia ("Wohlwollen"). Define la benevolencia como la satisfacción por la felicidad -el bienestar- de los otros. Beneficencia, en cambio, es la máxima de convertir la benevolencia en un fin, y el deber para ello es la coacción del sujeto mediante su razón de aceptar esta máxima como una ley general ${ }^{18}$. Es deber de cada hombre ser benefactor, esto es, según sus capacidades, promover la felicidad de otros hombres en situaciones de necesidad, sin esperar algo a cambio por ello ${ }^{19}$.

Como se puede ver, Kant trata la cuestión de la ayuda a otro en una situación de necesidad en dos partes distintas. En términos muy simplificados, en la sección sobre doctrina del derecho, rechaza el carácter jurídico del deber de ayuda e incluso su status moral, mientras que en la doctrina de las virtudes y de la ética, reconoce el status moral y ético del mismo deber. Este tratamiento dualista del problema genera, a primera vista, alguna perplejidad.

Sin embargo, y tal como lo advierte Pawlik, aquí Kant es coherente con su paremia según la cual "la necesidad no conoce Derecho", que le impide reconocer en tal situación extrema de conflicto, no solamente un deber jurídico, sino que incluso la existencia de un deber moral de "solidaridad". Esta consecuencia se explica, a su vez, porque el Derecho y la moral pertenecen a planos diferentes -uno a la esfera externa de las acciones y la otra a la esfera interna de los fines, sin que pueda existir, por ende, un conflicto entre ambos. La juridicidad es presupuesto de la virtud, o dicho con las palabras del filósofo, es la doctrina de las virtudes la que ordena al hombre respetar sagradamente el Derecho ${ }^{20}$. Por consiguiente, así como nunca puede calificarse de virtuosa -ética- la acción de ayudar a otro en necesidad al costo de un quiebre del derecho, tampoco puede existir un deber de virtud cuyo contenido radique en tolerar ese atentado por parte del otro ${ }^{21}$.

A diferencia de la concepción expuesta, Hegel afirma la existencia de un derecho de necesidad, pero frente a una situación de conflicto distinta. Se trata de la colisión entre, por un lado, la vida como ser personal en su totalidad -“conjunto de los fines"- y, por el otro, la propiedad jurídica como elemento determinado del ser de la libertad ${ }^{22}$.

Antes de tematizar este conflicto, Hegel suscribe un concepto negativo de Derecho en la sección sobre Derecho abstracto, en el sentido de que su alcance se reduce al mandato

6 Kant (1978) introducción en la doctrina de las virtudes, A 27 p. 524 y s.

Kant (1978) A 40, 41, p. 532 y s.

KANT (1978) doctrina elemental de la ética, § 29, p. 588 y s.

9 Kant (1978) § 30, p. 589.

Kant (1978) doctrina de las virtudes, A 28, 29, p. 525.

1 PAWLiK (2002) pp. 20 y ss.

2 Hegel (1970) § 127. 
de ser persona y respetar a los otros como personas, es decir, que se limita a lo negativo, i.e. no lesionar la personalidad y lo que se sigue de ella ${ }^{23}$. Asimismo, concibe la propiedad en los términos de que la persona debe darse a sí misma una esfera externa de su libertad para ser idea ${ }^{24}$. En la misma sección sobre Derecho abstracto, define la vida como totalidad abarcadora de la actividad externa, que, entonces, no es algo externo a la personalidad, sino que, por el contrario, se identifica con esta ${ }^{25}$.

Pues bien, en la sección sobre moralidad como estadio ya avanzado del Derecho -encarnación este de la idea de libertad- pero aún previo al de la eticidad, Hegel afirma la existencia de un derecho de necesidad de la vida en peligro último y en colisión esta con la propiedad jurídica de otro. Puesto que, de un lado, se encuentra en juego "la lesión infinita del ser y con ella la total ausencia de Derecho", mientras que, del otro, se encuentra en cuestión "solamente la lesión de un ser individual y restringido de la libertad"26.

En una adición al § 127 de la "filosofía del Derecho", Hegel aclara que "es necesario, empero, solamente vivir ahora, pues el futuro no es absoluto y queda entregado a la casualidad”. Por ende, solamente la necesidad del presente inmediato puede justificar una acción antijurídica, ya que su omisión implicaría la realización del injusto más grave, cual es "la negación total del ser de la libertad" 27 . Concluye advirtiendo que la necesidad deja de manifiesto la finitud y con ella la casualidad tanto del Derecho aislado, sin referencia a la vida concreta del individuo, como del bien ("Wohl") aislado, sin un fundamento substancial en el Derecho ${ }^{28}$. Las dimensiones del bien y de la consciencia ("Gewissen”) recién se alcanzan y unifican en el estadio de la eticidad ${ }^{29}$.

\subsection{REFORMULACIÓN CONTEMPORÁNEA DEL CONFLICTO: JUSTICIA Y SOLIDARIDAD}

El uso de la palabra "solidaridad" comienza a extenderse en la segunda mitad del siglo XIX y sirve, en el discurso político, de motor para el impulso de la seguridad social y del posterior Estado social ${ }^{30}$. Pero, es recién durante el siglo XX en que la palabra se vuelve como tal objeto de reflexión filosófico-política. En este contexto, sirve como justificación racional de un deber en una situación de necesidad y se contrapone así a la idea de justicia o de Derecho.

\footnotetext{
${ }^{23}$ Hegel (1970) §§ 36, 38; Hegel (2010) § 7, donde niega la existencia de mandatos positivos en el Derecho; cfr. Hösle (1998) p. 491 y s., quien incluso sostiene, en un lenguaje dogmático bastante inusual para un filósofo, que en base a estas consideraciones de Hegel no puede fundarse la punibilidad de la omisión de socorro, a lo más podría fundarse la de los „delitos impropios de omisión (esto es, dada una posición de garantía basada en la injerencia etc.)...".

24 Hegel (1970) § 41.

25 Hegel (1970) § 70.

26 Hegel (1970) § 127.

27 Hegel (1970) § 127 (adición).

28 Hegel $(1970) \S 128$.

29 Hegel (1970) § 136 y § 141; cfr. Hösle (1998) pp. 520 y ss.

30 Cfr. Bourgeois (1902) pp. 8 y ss.; GuZmán Dalbora (2016) pp. 73 y ss. prefiere la noción de fraternidad a la de solidaridad, pues esta permite que se haga el bien a otros manteniendo una relación "vertical", en cambio, la fraternidad presupone una relación horizontal; sin embargo, ese significado de la solidaridad no es el que se explicita a continuación, sino que uno más bien coincidente con el significado de la fraternidad como principio y valor.
} 
En algunos planteamientos filosófico-políticos, empero, tal conflicto se formula también en los términos de una oposición entre deberes negativos y deberes positivos, es decir, de un modo muy similar a la discusión desarrollada en el ámbito de la ciencia del Derecho penal.

En este sentido, Bayertz contrapone los deberes negativos o de omisión a la solidaridad. Los primeros serían universales e imparciales, mientras que la segunda sería por definición particular y parcial. Advierte que los vínculos de solidaridad en una comunidad no pueden justificar la provocación de un daño a otros, esto es, la infracción de un deber negativo. En consecuencia, Bayertz parte del supuesto de una preeminencia de la justicia por encima de la solidaridad, pero sin dejar de ofrecer una justificación para esta ${ }^{31}$. Esta preeminencia, a su vez, se explica sobre la base de entender el concepto de solidaridad en su sentido "social" o "ciudadano-estatal".

Esta forma de plantear la contraposición, por un lado, supone la paremia kantiana de la inexistencia de un derecho en la situación de necesidad, ergo, que impide la justificación de la acción antijurídica por infringir un deber negativo. Por otro, cuando se habla allí de solidaridad, se usa la palabra en el sentido de "solidaridad social", esto es, vinculado a la idea de Estado social -vid. infra 4.3.

Un contraste similar se ha planteado en base a la diferenciación de esferas de la moral. Así, Steinvorth opone la justicia a la beneficencia, en tanto "la justicia prohíbe que vulneremos los derechos de otro" y reconoce, entonces, derechos a cada hombre solamente por serlo y no por pertenecer a un grupo determinado. Entre estos derechos se incluye la libertad frente a los daños que los hombres pueden infligirse entre sí. La justicia fijaría de este modo el límite de lo permitido y lo prohibido entre los hombres. Lo que ella exige sería derecho y su cumplimiento constituiría el mínimo que debe hacerse para comportarse moralmente.

En cambio, según Steinvorth, la beneficencia ordenaría prestar ayuda a todos los necesitados, es decir, supone extrapolar el modelo de comportamiento propio de la familia a las relaciones entre los hombres. Señalaría la dirección en la cual debe irse cuando se pretende obtener la aprobación desinteresada por las acciones propias. Lo que exige es moralmente bueno y aquello que no se corresponde con ella no necesariamente se encuentra prohibido ${ }^{32}$.

En esta formulación del contraste se subraya el carácter universal de la justicia, al mismo tiempo que se vincula e identifica este valor con la idea de Derecho. Situada en otra esfera, la beneficencia se identifica con la solidaridad -vid. infra 3., de tal forma que ambas quedan relegadas al ámbito de la moral y, por ende, sin que puedan adquirir relevancia en el plano del Derecho.

A veces la diferencia entre deberes negativos y positivos se acentúa de tal manera que llega a formularse en los términos de una contradicción. En este sentido, Denninger se refiere a un deber positivo permanente, ilimitado e inagotable y, además, definido en su alcance por otro, sin observar el ejercicio propio de la libertad. Bajo esta comprensión, el

\footnotetext{
31 BAYERTZ (1998) pp. 22, 49 y s.

32 STEInVorth (1998) p. 63 y s
} 
deber positivo entraría en abierta contradicción con la libertad. Así, concluye que obrar por solidaridad y hacerlo en virtud de un deber jurídico se diferencian, por su motivación y alcance, tan esencialmente "como el fuego y el agua" 33 .

\subsection{VALORACIÓN INTERMEDIA}

Estos pasajes, por cierto, seleccionados de la filosofía política contemporánea, identifican, de un lado, los deberes negativos con la idea de justicia y de Derecho y, del otro, los deberes positivos con la idea de solidaridad e incluso de beneficencia. En este esquema, los deberes negativos -o de omisión- son manifestaciones del concepto de justicia y, por ende, en este sentido se habla de "deberes de justicia". Los deberes positivos -o de acción, en cambio, se identifican con el principio de solidaridad y el valor de la beneficencia, sin introducir mayores diferenciaciones en este plano. La formulación del contraste en estos términos, entonces, supone que la diferencia entre deberes negativos y deberes positivos no hace más que replicar la frontera misma entre Derecho y moral.

Sin embargo, y por una parte, existen deberes positivos que ostentan un status equivalente a los deberes negativos, en la medida que derivan de una institución regulada por el Derecho $-v . g r .:$ matrimonio y familia ${ }^{34}$. Se trata de los deberes positivos así llamados especiales e institucionales. Si uno parte de esa premisa, entonces tales deberes positivos se desglosan del ámbito de la moral y se ubican más bien en el plano del Derecho, existiendo, por ende, una relación simétrica entre los deberes negativos y solamente este conjunto de deberes positivos -especiales e institucionales ${ }^{35}$.

Por otra parte, la identificación un tanto apresurada de los deberes positivos en general con la solidaridad y, al mismo tiempo, de esta con la beneficencia, aleja tales deberes del concepto de justicia y tiende a relegarlos definitivamente al ámbito de la moral. Esta tendencia, empero, es demasiado indiferenciada como para ser suscrita.

\footnotetext{
33 Denninger (1998) p. 337.

${ }^{34}$ Cfr. Jakobs (1993) cap. I, Apdo. 7, núm. marg. 70; el reconocimiento de la existencia de deberes positivos especiales e institucionales que ostentan el mismo status de los deberes negativos implica solamente que su infracción puede conducir a la misma clase de responsabilidad penal. Pero, también cuando se trata de la infracción de tales deberes positivos es preciso observar los diversos criterios de imputación objetiva, como el riesgo permitido, el principio de autorresponsabilidad de la víctima, el así llamado principio de confianza u otro criterio de imputación del resultado, v.gr.: conducta alternativa hipotética conforme a deber. Lo que ocurre en los casos de omisión es que no puede hablarse propiamente de la "creación del riesgo prohibido", simplemente porque allí se trata del incumplimiento del deber ante la situación de peligro, de modo que es necesario extraer el contenido netamente normativo de cada criterio de imputación objetiva y aplicarlo en el caso concreto, justamente este alcance valorativo y normativo es lo que distingue tales criterios de la causalidad. Por ejemplo, el padre se encuentra vinculado por un deber positivo especial e institucional en relación con su hijo menor de edad, pero la formación y educación de los hijos implica correr algunos riesgos generales de la vida en sociedad, de tal forma que si la situación de peligro en el caso concreto se mantiene bajo ese estándar de riesgo permitido, no habría infracción del deber positivo si el padre no interviene frente a ese peligro. Los criterios de imputación objetiva son igualmente aplicables tanto respecto de los deberes negativos como de los deberes positivos.

35 Cfr. van Weezel (2018) p. 1088; en contra, Robles (2013) pp. 9 y ss.
} 


\section{DIFERENCIACIÓN ENTRE EL DEBER GENERAL DE AUXILIOY LOS DEBERES DE BENEFICENCIA}

Tal tendencia, además, que identifica sin más la solidaridad con la beneficencia, es bastante contraintuitiva. En particular, resulta bien difícil considerar sinónimos el deber general de auxilio y el deber de beneficencia, pues, así concebidos implicaría calificar de un mero deber moral de benevolencia la ayuda prestada por un sujeto en favor de otro que se encuentra en una situación de peligro existencial. Por ejemplo, el paseante se encuentra casualmente con un niño que ha caído en una poza, de la cual aquel puede sacarlo sin más. El niño se encuentra en una situación de peligro vital. Pues bien, al socorrerlo el paseante no mejora en un ápice el status quo del niño, solo lo retrotrae al mismo estado previo a la ocurrencia de la situación de peligro ${ }^{36}$. No lo beneficia en nada ni mucho menos construye un mundo en común con él.

En contra de la tendencia en cuestión, Mieth sostiene que algunos deberes positivos pueden calificarse de "fuertes" y, por ende, son susceptibles de ser agrupados bajo los "deberes de justicia", en tanto su contenido se encuentre referido a bienes elementales de la persona ${ }^{37}$.

La filósofa de influencia kantiana diferencia nítidamente tres clases de deberes positivos: deberes de cuidado y de garante (1.), de auxilio en necesidad (2.) y deberes de beneficencia (3.). Esta clasificación conduce a una tripartición de los deberes positivos ${ }^{38}$.

En primer lugar, se encuentran los deberes de cuidado y de garante, que se caracterizan por derivar de una conducta previa del obligado y, además, por dirigirse a personas cercanas, por ejemplo, los padres respecto de sus hijos. Por esta doble característica, tal clase de deberes se distingue de los demás deberes positivos (1.).

Pero, según Mieth, y en esto radica su aporte, no todos los restantes deberes positivos se agrupan sin más entre los deberes "débiles" de beneficencia. Pues, existen deberes positivos fuertes en la medida en que se refieren a bienes necesarios y que, además, se encuentran determinados según criterios tales como la competencia y la perspectiva de éxito (2.).

El reconocimiento de la existencia de deberes positivos "fuertes" implica que, en el caso de un conflicto con deberes negativos, pueden prevalecer sobre esta clase de deberes, por ejemplo, se puede dañar la propiedad ajena para salvar la vida de otro. Esta consecuencia supone que en esa situación de conflicto puede infringirse un deber negativo para así cumplir un deber positivo, siempre que este pueda calificarse de "fuerte". Este caso, por cierto, evoca el conflicto entre vida y propiedad planteado por Hegel en su filosofía del Derecho-vid. supra 2.1.

Si se habla de deberes de justicia y estos se identifican con los deberes "fuertes", entonces el planteamiento expuesto implica que los deberes de justicia pueden ser tanto negativos como positivos. Los deberes de justicia suponen la existencia correlativa de derechos. Por consiguiente, su infracción configura un injusto, y esto sería común tanto a los deberes negativos como a los deberes positivos de justicia. En este punto, y tratándose de estos de-

\footnotetext{
Cfr. Garzón Valdés (1986) p. 20 y s.; también Mieth (2012) p. 67.

7 Mieth (2012) p. 112 y s.

38 Mieth (2012) pp. 114 y ss.
} 
beres positivos "fuertes", tal planteamiento se aparta de los expuestos precedentemente, que tienden a relegar en su totalidad los deberes de solidaridad al ámbito de la moral y, en consecuencia, califican su infracción como un mero ilícito moral.

A diferencia de esa clase de deberes positivos, los deberes "débiles" de beneficencia se refieren a bienes no necesarios. $\mathrm{O}$ también pueden referirse a bienes necesarios, pero en este segundo caso tales deberes se encuentran infradeterminados - de ahí su carácter débil. Los deberes de beneficencia propiamente tales se caracterizan porque su contenido radica en el mejoramiento general del bienestar ajeno. Por ende, el otro no tiene una pretensión correlativa al cumplimiento del deber (3.).

$\mathrm{Al}$ interior de los deberes positivos, entonces, Mieth subraya la diferencia entre el deber de auxilio en necesidad y los deberes de beneficencia. El alcance del deber de auxilio en necesidad se restringe a bienes necesarios. Para distinguir entre bienes necesarios y bienes no necesarios, recurre al criterio de la necesidad objetiva. De acuerdo a este criterio, tal situación de necesidad concurre cuando se encuentran involucrados los presupuestos mismos de la capacidad autónoma de acción. El cumplimiento de tal deber se dirige a mantener bienes necesarios y reestablecer así dicha capacidad, esto es, la autonomía del sujeto ${ }^{39}$. A su vez, esta se entiende en su sentido kantiano, es decir, como la facultad de legislarse a sí mismo, de autodeterminarse según leyes generales, en síntesis, se refiere a la acción responsable ${ }^{40}$.

Finalmente, Mieth formula lo que llama el "principio de ayuda", recurriendo a una serie de criterios restrictivos, tales como la competencia, la exigibilidad, la licitud de la ayuda y la perspectiva de éxito: "Un derecho moral al auxilio existe para B, cuando (a) este se encuentra en una situación objetiva de necesidad (por lo que tiene una pretensión de auxilio), para A es posible ayudar a B, (b) A es competente, (c) el esfuerzo para el auxilio es exigible, (d) los medios usados son lícitos y (e) la ayuda tiene perspectiva de éxito. Si concurren estos criterios, A tiene un deber de ayuda fuerte ante B" 41 .

Mieth es filósofa y es por eso que habla aquí de un "derecho moral”, para así realzar el status del deber general de auxilio y diferenciarlo luego del deber de beneficencia. El sujeto que se encuentra en una situación de peligro existencial, entonces, ostenta tal derecho que es correlativo a un deber positivo "fuerte" como es el deber general de auxilio.

En esa medida, es plausible sostener que este deber general ostenta al menos un status intermedio entre los deberes negativos de justicia y los deberes positivos de beneficencia. Es decir, se ubica en una posición asimétrica con respecto a los deberes negativos, pero, al mismo tiempo, no ocupa la misma posición ni se sitúa en el mismo plano que los deberes de beneficencia.

\subsection{UNA REFLEXIÓN FILOSÓfiCA Y SOCIOlÓgICA PREVIA: HabermaS y MEAD}

Para darle un sustento material a esta diferenciación entre el deber general de auxilio y los deberes de beneficencia al interior del principio de solidaridad, son necesarias algunas reflexiones filosóficas y sociológicas acerca de la relación entre individuo y comunidad.

\footnotetext{
39 Mieth (2012) pp. 144, 147, 153 y s.

40 Mieth (2012) pp. 148 y s., 150.

41 Mieth (2012) pp. 156 y s.
} 
En este orden de consideraciones, también Habermas parte de la diferenciación entre justicia y solidaridad, junto con reconocer que esta no deriva simplemente de aquella. Advierte que a partir del respeto por la integridad de una persona frágil, en estricto rigor, no se sigue la preocupación por su bienestar ${ }^{42}$. Dicho de otra forma, a partir del mandato de respeto al otro como persona no se deriva simplemente el deber de preocuparse por su bienestar.

Según Habermas, la persona forma un centro interno y se convierte en individuo solamente en tanto ella se enajena en el seno de las relaciones interpersonales producidas comunicativamente. Suena algo paradójico decir que el individuo se forma como tal en un proceso de enajenación, esto es, de volverse otro. Una explicación muy iluminadora de esta paradoja, empero, proviene del sociólogo norteamericano George Herbert Mead, a cuya teoría Habermas recurre para luego abordar la relación entre justicia y solidaridad ${ }^{43}$.

La tesis central de Mead radica en que la identidad se constituye del "yo" y del "mi". Su gran aporte teórico, no obstante acuñarse en clave behaviorista, consiste sin duda en esta distinción ${ }^{44}$. Formulada en esos términos, el "yo" es la reacción del organismo al comportamiento de los otros, mientras que el "mi" es el conjunto organizado de conductas de los otros que uno internaliza ${ }^{45}$.

La comunidad organizada o el grupo social, que sustenta la identidad del individuo, se denominar "el otro generalizado" 46 . Así, el "mi" resulta de la internalización de ese "otro generalizado" mediante la interacción entre el "yo" y la comunidad. Internalizamos el comportamiento de la comunidad frente a nuestra reacción en vista del sentido de nuestra actividad. Mead llama "mi" al contenido experiencial inmediato de la propia identidad junto con ese comportamiento. Esta es la identidad que se realiza en la comunidad y que es reconocida en ella en tanto aquella reconoce a los otros ${ }^{47}$.

Si lo anterior es correcto, entonces no es posible trazar una línea de separación estricta entre nuestra propia identidad y la identidad de otros hombres. Pues, nuestra identidad existe y como tal se integra a nuestra experiencia solamente en la medida en que existen las identidades de otros y como tales se integran también en nuestra experiencia: "el individuo tiene una identidad solamente en relación con las identidades de otros miembros de su grupo social" 48 .

En otro lugar, Mead señala que el hombre es un ser racional, porque es un ser social, o dicho de otra manera, la racionalidad se funda en la socialidad: "somos lo que somos mediante nuestra relación con los otros" ${ }^{\prime 2}$.

\footnotetext{
42 Habermas (1986) p. 309.

43 Habermas (1981) T. 2, p. 9, sitúa a Mead nada menos que entre los padres fundadores de la sociología junto a Max Weber y Émile Durkheim.

44 Cfr. Habermas (1981), T. 2, pp. 62 y ss., sobre Mead; la identidad se construye del „Me“ (comparable al super-yo de Freud) y del „I“ (yo), pp. 66 y s., 92 y s., 152 y s.

45 MEAD (1973) p. 218.

46 MeAd (1973) p. 196

47 MeAd (1973) pp. 239 y s. (p. 241: "el 'mi' es una esencia prefigurada por convenciones y costumbres").

48 MeAd (1973) p. 206.

49 MeAd (1973) "Fragmente über Ethik" pp. 429 y s.
} 
De este modo, y dado que los hombres se han individuado mediante socialización de tal forma que no pueden por sí solos afirmar su propia identidad, Habermas sostiene que la integridad del individuo no puede conservarse sin reafirmar la integridad de su mundo común de la vida, en tanto este posibilita las relaciones interpersonales y de reconocimiento recíproco. Desde una perspectiva teórico-comunicativa, existe una estrecha conexión entre el cuidado por el bienestar del prójimo y el interés por el bienestar general: "la identidad del grupo se reproduce sobre la base de relaciones intactas de reconocimiento recíproco" 50 .

Luego, Habermas extrae las consecuencias del análisis precedente para el nexo entre justicia y solidaridad. Según el filósofo de Frankfurt, el punto de vista complementario al trato igualitario e individual -justicia- no es la benevolencia, sino que la solidaridad. Este principio hunde sus raíces en la experiencia de que uno debe responder por el otro, puesto que, en tanto "compañeros", todos deben estar igualmente interesados en la integridad de su relación común de vida: "la justicia conceptualizada deontológicamente exige solidaridad como su otro" 51 .

Entonces, la solidaridad es el otro de la justicia, i.e. es su contracara. La justicia tiene por objeto a las libertades iguales de los individuos únicos y determinados por sí mismos -autodeterminación. Vela por la intangibilidad de los individuos socializados en la medida que exige trato igualitario y así igual respeto a la dignidad de cada uno. Por su parte, la solidaridad se refiere al bienestar de los compañeros hermanados en una forma de vida intersubjetivamente compartida y, de este modo, supone también la conservación de la integridad de esa forma de vida misma ${ }^{52}$.

Comprendida de ese modo, por ende, la solidaridad sí puede ser en esa medida objeto de universalización. Este punto de vista permite así matizar el contraste antes trabado entre una justicia universal y una solidaridad particular. Por lo menos aquella dimensión de la solidaridad que atañe a la conservación de la integridad del mundo común de la vida, sí es susceptible de ser universalizada.

En este sentido, el propio Mead sostiene que la socialidad es la razón de la universalidad de los juicios éticos y propone luego dotar de contenido a la regla de oro kantiana mediante la consideración de dicho carácter social y de todos los intereses involucrados ${ }^{53}$.

Por su parte, Habermas propone recurrir a la ética del discurso a fin de volver convergentes la justicia con la solidaridad como su otro ${ }^{54}$. El concepto moderno de justicia solo puede realizarse si la ética del discurso enfrenta la unilateralidad individualista y realza la solidaridad como la contracara de la justicia. En la discusión han de incluirse los aspectos estructurales de la "vida buena" que generalmente, bajo el punto de vista de la socialización comunicativa, pueden desglosarse de las totalidades concretas a partir de las respectivas formas especiales de vida ${ }^{55}$.

50 Habermas (1986) pp. 310 y s.

51 Habermas (1986) p. 311.

52 Habermas (1986) p. 311.

53 MeAd (1973) pp. 436 y ss.

54 Habermas (1986) pp. 312 y ss.

55 Habermas (1986) p. 314; también antes Habermas (1981) T. 2, pp. 140 y ss., 150 y ss. 


\subsection{Algunas reflexiones filosóficas desde la ciencia del Derecho penal}

En el ámbito de la ciencia del Derecho penal, la relación entre individuo y comunidad ha sido abordada para los efectos de explicar el fundamento del deber general de solidaridad que subyace a la norma sobre omisión de socorro -v.gr.: § 323 c StGB. Una propuesta muy fundada filosóficamente, pero algo bizarra en su formulación y, sobre todo, en una de sus conclusiones -el deber general de socorro rige solamente cuando el sujeto se encuentra solo con la víctima de la situación de peligro, ha sido desarrollada por Harzer.

La orientación general de su trabajo es muy interesante, entre otras razones, porque recupera la antigua categoría de la relación jurídica, caída posteriormente en el olvido con el desarrollo de la teoría general del derecho y su concentración desmesurada en la teoría de las normas ${ }^{56}$. Su propuesta parte de una ampliación del principio de libertad en sentido kantiano: "el individuo no es más el ser de la voluntad finito e individual, sino que se funda en el conocimiento de la relación externa hacia el otro" ${ }^{57}$. Recuerda asimismo un concepto de Savigny, según el cual la relación jurídica es una "relación entre persona y persona determinada por una regla jurídica" 58 .

Para dotar de contenido a la relación jurídica, Harzer recurre al concepto de "unión" ("Bündnis"), en el sentido de que aquella es un vínculo de los participantes en el cual el individuo frente al otro $-y$ este frente a aquel- no pierde su propia autoconsciencia. En un lenguaje algo críptico, sostiene que tal nexo no es un contrato, sino que antes bien es "la refundición del resultado de la fuerza cognitiva individual en relación con la situación recíproca espacial y temporalmente común”. Unión sería un lazo trascendental de autonomías igualmente significativas, que reviste cualidades de compañerismo ${ }^{59}$.

La relación jurídica sería el vínculo de libertad originariamente autodeterminado que se concreta mediante una situación formulada legalmente, en la cual la prestación prácticosocial de dos o más personas se intermedia temporal y espacialmente ${ }^{60}$. La prestación de auxilio es accesoria en el sentido de que implica una situación derivada y secundaria que exige el cumplimiento de tareas mediante fuerzas de orden ya activas, pero insuficientes. $Y$ el caso en el cual estas fuerzas personales competentes todavía no intervienen ni prestan activamente auxilio supone la situación secundaria de la ausencia de conocimiento ${ }^{61}$.

De esa manera, por cierto algo enrevesada, Harzer da cuenta del carácter subsidiario del deber general de auxilio del ciudadano. Así, el sujeto común en tanto persona individual se convierte en fuerza competente que puede poner en movimiento la relación jurídica en su significado igualitario y recíproco: "el deber jurídico de intervención existe sola y exclusivamente en ese ámbito del origen recíprocamente reconocido de la prescindencia de

\footnotetext{
56 Harzer (1999) pp. 170 y ss.; se le podría retrucar, empero, que la justificada recuperación de la categoría de la relación jurídica no tiene por qué implicar un menosprecio a la teoría de las normas, por el contrario, es perfectamente viable desarrollar una teoría de las normas con sustento en la categoría de la relación jurídica.

57 Harzer (1999) pp. 170 y s.

58 HaRzer (1999) p. 181.

59 Harzer (1999) p. 183.

60 HaRzer (1999) p. 185.

${ }^{61}$ Harzer (1999) p. 197.
} 
prestaciones". Es decir, cuando el sujeto es al mismo tiempo la única persona de la relación jurídica que puede conservar esa relación como un mundo no fraccionado ${ }^{62}$.

También desde una perspectiva filosófico-jurídica, que hunde sus raíces en la tradición de Kant y de Hegel, Köhler parte de la existencia de un deber jurídico, cuya generalización institucional recién da lugar a la previsión estatal ${ }^{63}$. Es decir, se trata de un deber de la persona individual, que luego se generaliza y así da sustento a la seguridad social. Su fundamento reside en el mandato normativo de la razón de existir autónomamente: "la autoafirmación jurídica de la subjetividad libre”.

En el marco de una concepción ampliada de la garantía de libertad positiva han de incluirse los presupuestos básicos de la existencia personal. De ello resulta, primero, la participación originaria y jurídico-humanitaria en los bienes de la tierra en una medida mínima suficiente para la existencia autónoma. Esta faceta se expresa, por ejemplo, en el derecho de asilo, el derecho a una ayuda social mínima y en la facultad de interferir en la propiedad ajena en situación de necesidad existencial. Por otro lado, dicha participación originaria alcanza el status de un derecho a la actividad de otros frente a una situación de necesidad existencial y casual, en cierto modo un derecho originario de participación en el arbitrio ajeno: "la casualidad externa contradice en sí misma el ser cabalmente desarrollado de los sujetos libres". El deber a la autoafirmación del ser racional se traduce, a su vez, en un deber general de evitar en lo posible la exposición a esa casualidad externa ${ }^{64}$.

Para los sujetos de derecho y deber, se trata de un deber general humanitario, que luego se concreta según el estadio de desarrollo de la organización jurídica ${ }^{65}$. El alcance del deber radica en el auxilio posible ante la necesidad existencial y casual del otro, esto es, no generada por este ni por el propio obligado. Según su contenido objetual, el deber de auxilio se refiere a la libertad externa jurídica ante la necesidad existencial y casual ${ }^{66}$.

\subsection{UNA SÍNTESIS INTERMEDIA: FUNDAMENTO DEL DEBER GENERAL DE AUXILIO}

Las reflexiones latamente expuestas, que provienen tanto del campo de la filosofía política y jurídica como de la teoría sociológica, permiten ensayar una síntesis intermedia. Esta supone una reinterpretación de la situación de peligro existencial que funda el limitado derecho de necesidad asumido por Hegel en el $§ 127$ de la filosofía del Derecho -vid. supra $2.1^{67}$.

\footnotetext{
${ }^{62}$ Harzer (1999) p. 202, también p. 214.

63 KÖHLER (1997) p. 207.

${ }^{64}$ KÖHLER (1997) p. 208.

65 KÖHLER (1997) pp. 208 y s.

66 KöHler (1997) p. 209; en cuanto al alcance del deber, similar Harzer (1999) p. 216.

${ }^{67}$ Acertadamente van WeEzel (2018) pp. 1090 y ss., 1097 y ss., muestra que la justificación del derecho de necesidad ante esta situación de conflicto en la sección sobre moralidad se integra luego y dialécticamente en el estadio ulterior de la eticidad; esta consideración y ubicación sistemática del derecho de necesidad ya en dicha sección de la filosofía del Derecho, permite fundarlo intersubjetivamente de modo previo a su institucionalización estatal. El presente trabajo suscribe la propuesta interpretativa de van Weezel en orden a que, como sostiene, "el deber de solidaridad no está mediado por el Estado, sino que existe ya en la relación interpersonal" (p. 1099), propuesta que se aparta, en definitiva, de la interpretación ofrecida por PAWLIK (2012) pp. 191 y s. Van Weezel se funda, además, en el concepto de amistad en Aristóteles, van Weezel (2018) p. 1099: "Pero un
} 
Pues bien, lo que en tal situación se encuentra en peligro no es solamente la existencia individual en su totalidad, sino que el "otro generalizado" e internalizado por el sujeto en su interacción con la comunidad y que constituye, asimismo, su identidad: el "mi” en los términos de Mead. Se encuentra en juego la relación común de vida, en el sentido de Habermas, que le da sustento a las relaciones interpersonales y de reconocimiento recíproco, en cuyo contexto el sujeto se socializa e individua.

El punto es que esta relación constitutiva no existe con independencia del Derecho $^{68}$. En la comunidad jurídicamente organizada, el proceso de socialización e individuación del sujeto se produce siempre en el marco del Derecho. Se trata, entonces, también de la relación jurídica en el sentido recuperado por Harzer. Es esta relación la que se encuentra asimismo en cuestión. Bajo esta premisa, la situación de peligro existencial activa el deber originario de conservar la integridad de la relación común de vida, que por eso Köhler califica de jurídico-humanitario.

Este deber es correlativo al derecho de necesidad en el sentido de Hegel. Pero, el sentido del cumplimiento de este deber no se agota meramente en el rescate de la vida e integridad del otro, esto es, del "yo" de este, por decirlo nuevamente en los términos de Mead. Al cumplir este deber originario en la situación de necesidad existencial del otro, el sujeto rescata aquello que los une, i.e. el lazo que es constitutivo de ambos. Por eso es que se trata de un deber que ha cumplirse con cualquier otro portador de rostro humano ${ }^{69}$.

\section{LA ESTRUCTURA DEL PRINCIPIO DE SOLIDARIDADY SU RELACIÓN CON EL ESTADO SOCIAL}

Históricamente, la legislación penal, al menos en la órbita de la tradición jurídica europeo-continental, siempre ha partido de la premisa básica de la existencia de un deber general de socorro o auxilio frente a una situación de peligro existencial del otro ${ }^{70}$. Fiel a esta tradición, el legislador nacional del siglo XIX incluyó las normas de los artículos 494 No 14 y 496 No 2 en el CP varias décadas antes de que surgiera la "cuestión social" y el subsecuente desarrollo siquiera incipiente de la seguridad social. De alguna manera, el legislador de la época partió también de la existencia obvia de un deber general de socorro y de colaboración con el Estado frente a situaciones de peligro común.

\footnotetext{
mínimo de amistad entre los ciudadanos, precisamente bajo la forma de mínima solidaridad, pertenece al núcleo de lo que constituye la identidad social".

68 Cfr. Habermas (1992) pp. 51 y ss., sobre el Derecho moderno como fuente secularizada de integración social; tal función la cumple el Derecho, sin embargo, en la medida en que no se reduce a la sola legalidad, sino que plantea al mismo tiempo la pregunta por su legitimación, cuestión que, a su vez, supone que el ciudadano amplía su rol más allá de la posición egoísta "vacío de solidaridad" que deja la concepción kantiana del Derecho- e interviene como ciudadano estatal, haciendo uso de la acción comunicativa.

69 Cfr. LÉvinas (1971) p. 43: "La forma en que el otro se presenta, superando la idea del otro en mí, la llamamos, en efecto, rostro"; "el rostro es presencia viviente, es expresión (...) el rostro habla” p. 61; pp. 73 y ss., 211 y ss.

70 Cfr. Vermander (1969) pp. 4 y ss.
} 


\subsection{Diferenciación entre deber general de auXilio y Estado social}

A nivel filosófico, ya se ha mencionado que Hegel, en la filosofía del Derecho, reconoce un derecho de necesidad ante la situación de conflicto entre vida y propiedad en el acápite sobre moralidad como estadio ya avanzado de desarrollo del Derecho. En ese lugar, aclara que tal derecho se ejerce solamente para vivir ahora, en el presente, "pues el futuro no es absoluto y queda entregado a la casualidad"71.

Mucho después, en la sección sobre eticidad como estadio final de la idea de libertad, Hegel trata a propósito de la sociedad civil el sistema de la dependencia recíproca en el cual se funda la subsistencia y el bien del individuo así como su calidad jurídica en la subsistencia, i.e. el bien y el derecho de todos entrelazados, que solo en ese contexto se vuelven reales y asegurados ${ }^{72}$. Asimismo, distingue tres momentos de la sociedad civil, empezando con el sistema de las necesidades que supone la canalización de estas y la satisfacción del individuo tanto mediante su propio trabajo como por medio del trabajo y de la satisfacción de las necesidades de todos los demás. Luego, la protección de la propiedad mediante un sistema de justicia. Y, en tercer lugar, la previsión frente a la casualidad que resta en ese sistema así como el cuidado del interés particular en tanto común mediante la policía y la corporación ${ }^{73}$.

Pues bien, es recién en este último momento de la sociedad civil donde Hegel trata "lo subjetivo de la pobreza y de la necesidad de toda clase" y también la miseria como hundimiento de una masa relevante de la población bajo el nivel de una cierta forma de subsistencia, que al mismo tiempo trae consigo la concentración de la riqueza desmedida en pocas manos ${ }^{74}$.

Este tratamiento sistemáticamente diferenciado del derecho de necesidad, en una parte, y de la "cuestión social", en otra, permitiría diferenciar también los deberes correlativos del ciudadano. Es decir, el deber correlativo al derecho de necesidad, por ejemplo, de tolerar un atentado a la propiedad para conservar la existencia, se diferenciaría a su vez de los deberes que el ciudadano puede asumir frente al Estado con motivo de la "cuestión social".

\subsection{PRINCIPIO DE SOLIDARIDAD y ESTADO SOCIAL}

Ahora bien, el desarrollo del Estado social responde justamente a la necesidad de hacerse cargo de este problema de la modernidad ${ }^{75}$.

En este sentido, Depenheuer distingue tres fases de desarrollo del Estado moderno, partiendo con la superación de la guerra civil mediante la garantía de seguridad física, etapa en la cual nace correlativamente el deber de paz del ciudadano. Le sigue la fase del

\footnotetext{
${ }^{71}$ Hegel (1970) § 127 (adición).

72 Hegel (1970) § 183.

73 Hegel (1970) § 188.

74 Hegel (1970) § 242 y $§ 244$; la idea de Estado social, sin embargo, no alcanza a ser desarrollada como tal en la filosofía del Derecho, así Hegel se mantiene como liberal, parece preferir "la moralidad presente a la futura eticidad", cfr. HösLE (1998) pp. 553 y s.

75 Bourgeois (1902) pp. 24 y ss., 52 y ss., parte, bajo la óptica del positivismo sociológico de Comte, de la vigencia de "leyes sociales naturales" entre las cuales se encuentra la "solidaridad natural", pero cuya realización supone la práctica de la "solidaridad social", pp. 73 y ss.
} 
Estado de Derecho propiamente tal, fase en la cual se otorga seguridad jurídica mediante la garantía de la propiedad. Aquí el ciudadano se somete correlativamente a un deber de obediencia. Finalmente, la seguridad social se garantiza recién con el desarrollo del Estado social, en cuyo marco surge un deber inespecífico del ciudadano a la carga común, sin que exista una relación sinalagmática ${ }^{76}$.

Depenheuer sostiene que el ciudadano, en su calidad de titular de derechos fundamentales, se encuentra liberado de toda obligación solidaria inmediata, por lo que este puede decidir soberanamente sobre su alcance y dotarla así de contenido. Por su lado, el aspecto financiero de este deber de solidaridad se reduce a la carga tributaria ${ }^{77}$.

El jurista alemán se refiere aquí a una dimensión bien determinada del principio de solidaridad. Se trata de aquella dimensión que funge como sustento de la seguridad social y, con ella, del Estado social. La pregunta que luego se formula atañe al origen y fundamento de este componente central del principio de solidaridad.

Según Depenheuer, una explicación que pretenda retrotraerse a este origen no puede tomar al individuo aislado como punto de partida. Antes bien, para dar cuenta de ello, la teoría individualista del Estado debe renunciar parcialmente a la pretensión que surge de su interés de explicación racional e indagación por el fundamento total del Estado ${ }^{78}$. Pues, tal pretensión de fundamentación es excesiva ante la finitud del hombre. En tanto ser histórico, este siempre sigue siendo aquello que fue ${ }^{79}$.

En el momento originario del Estado de Derecho, los hombres ya vivían en un status civilis. Esta condición ya se encontraba dada, de modo que la pregunta básica de la teoría del contrato, advierte Depenheuer, era puramente hipotética, i.e. solo filosóficamente abierta. No estaba seriamente la disyuntiva de regresar al estado de naturaleza o de entrar en el estado jurídico. Antes bien, la disyuntiva consistía o en reducir la pregunta a la justificación de un Estado dado y ya existente o en ampliarla a los presupuestos de una forma estatal legítima: "En consecuencia, la pregunta básica de la teoría del contrato no se orientaba a responder por qué los hombres decidieron unirse en el Estado, sino más bien por qué los hombres aceptaron para sí su modo de existencia estatal dado en la forma en la cual ellos nacieron" ${ }^{80}$.

En este sentido, el punto de partida para la legitimación del Estado social no es el individuo aislado, sino que la comunidad. El Estado social se funda en la existencia previa de una "comunidad solidaria", que, según Depenheuer, ya se encuentra en el origen mismo del Estado de Derecho. Solo que, posteriormente, la organización jurídica de la libertad redujo la solidaridad ciudadano-estatal a su mínima expresión, i.e. la hizo caer en el olvi$\mathrm{do}^{81}$. Para justificar racionalmente el Estado social, entonces, es necesario conectar con ese

\footnotetext{
76 Depenheuer (2009) pp. 169 y ss., 178 y s.

77 Depenheuer (2009) pp. 194 y ss.; critica los intentos de redefinición de los derechos fundamentales de defensa en términos de incluir los derechos de participación social (pp. 190 y s., pp. 228 y s.).

78 Depenheuer (2009) pp. 262 y ss., 267 y ss.

79 Depenheuer (2009) p. 269.

80 Depenheuer (2009) p. 271 (destacado agregado).

81 Depenheuer (2009) pp. 186 y s.
} 
origen. En una expresión sintética tomada del filósofo Odo Marquard: "el futuro necesita origen" ("Zukunft braucht Herkunft") 82 .

Dicha comunidad solidaria, para serlo, supone ciertas características de homogeneidad y, por ende, de exclusividad. La homogeneidad describe una determinada relación de igualdad que se encuentra dada y no es disponible para el individuo. En este sentido, se trata de una "comunidad de delimitación", pues, sus integrantes comparten ciertas características como origen, lenguaje, género, historia y destino, de las cuales otros no participan. Lo anterior implica que los integrantes de la comunidad solidaria son más iguales entre ellos que en relación con los otros que no la integran, porque no comparten dichas características ${ }^{83}$. Además, supone una homogeneidad subjetiva, en el sentido de una consciencia de la pertenencia a la comunidad. La homogeneidad implica exclusividad, esto es, supone la existencia de hombres o grupos respecto de los cuales no se presta ayuda o atención ${ }^{84}$.

La existencia de una comunidad solidaria, entonces, que reviste tales características de homogeneidad y exclusividad, es el presupuesto básico del Estado social ${ }^{85}$. Es en su interior donde se desenvuelve lo que puede llamarse solidaridad social o ciudadano-estatal ${ }^{86}$.

Respecto de ella, Bayertz concluye: "Generalmente entendemos por 'solidaridad' el apoyo recíproco y para el otro entre personas que se encuentran unidas mediante determinadas características comunes. Se es 'solidario' con hombres cuya historia, convicciones o intereses uno comparte -en contraste con hombres cuya historia, convicciones o intereses uno no comparte" ${ }^{\mathrm{P}}$.

Esa dimensión del principio de solidaridad, y en esto se diferencia del deber general de auxilio -vid. supra 3.3 y 4.1, no es susceptible de ser universalizada. Pues supone una comunidad solidaria cuyos integrantes comparten las características de homogeneidad objetiva y subjetiva antes referidas. Tal dimensión, no obstante, se reduce a lo que puede llamarse "solidaridad social-estatal" 88 . Solo este componente del principio de solidaridad es indefectiblemente particular y parcial.

${ }^{82}$ Marquard (1981) p. 16 y s.

${ }^{83}$ Depenheuer (2009) pp. 274 y ss.; según la teoría del cierre implícito del contrato, se legitima el orden político mientras se permanezca voluntariamente en el territorio estatal, ya que siempre puede ejercerse la libertad de quedarse o de emigrar; si se permanece, concurre lo que plásticamente puede llamarse "aprobación con los pies" (p. 272 y s.); así también BAYERTZ (1998) p. 30 y s., recuerda que rige el precepto "nemo in communione potest invitus detineri", esto es, nadie se encuentra obligado a vivir en una comunidad y, al mismo tiempo, todos tenemos el derecho de emigrar.

${ }^{84}$ Depenheuer (2009) pp. 276 y s.; también Bayertz (1998) pp. 30 y s.

${ }^{85}$ En este sentido, también KühnBaCh (2007) pp. 153 y ss., 197 y s., 206 y ss.

${ }^{86}$ Bourgeors (1902) pp. 15 y s., "solidarité sociale": el hombre nace en el seno de una asociación humana, que es hereditaria de una cultura, un lenguaje, de instrumentos materiales y espirituales, libros, por ende, ya en su origen se encuentra obligado con las generaciones pasadas que crearon esa herencia y, al mismo tiempo, con las generaciones futuras para cultivarla, pp. 100 y ss., 116 y ss.; en el origen ya existe una deuda con los otros integrantes de esta asociación humana, una deuda social, ergo, una obligación previa, no sujeta a disposición; el derecho que rige esta relación prexistente se fija, entonces, no por el acuerdo de voluntades entre los integrantes, sino que mediante "una interpretación y una representación del acuerdo que se habría alcanzado previamente entre ellos si hubieren sido igual y libremente consultados", esto es, la presunción de un consentimiento, más bien, entonces, un cuasicontrato, pp. 132 y s.

87 BAYERTZ (1998) p. 21.

${ }^{88}$ Cfr. BAYERTZ (1998) pp. 34 y s. 
Ahora bien, el desarrollo del Estado social implica la juridificación e institucionalización de la solidaridad social. Desde el momento en que esta se formaliza y regula, ya no puede decirse que el personal de la burocracia estatal obra por "solidaridad" con los ciudadanos que, por ejemplo, le presentan una solicitud de subsidio. Lo mismo cabe advertir respecto de aquellos que financian estas prestaciones sociales mediante sus impuestos ${ }^{89}$.

\subsection{Fundamentos propios del Estado social}

Según Bayertz, la base de legitimación del Estado social ya no es, entonces, la solidaridad entendida de esa forma, sino que el principio de igualdad. Si la justicia social pasa a constituirse en un presupuesto de la integración plena a la comunidad política, también entonces debe poder reclamarse como un derecho, cuya realización es garantizada por el Estado. Las prestaciones social-estatales ya no se conciben como mera ayuda, sino que pasan a calificarse como una compensación por daños o derechos lesionados. La formación del Estado social es parte de un proceso en que tanto la pobreza como la necesidad de toda clase dejan de atribuirse a fenómenos de la naturaleza y, por el contrario, empiezan a ser vistos como consecuencias indirectas de decisiones y acciones humanas, es decir, como partes de un problema social ${ }^{90}$.

En esta misma dirección, Rawls formula el principio de diferencia y, en este marco, se refiere a la "fraternidad". Se trata de un concepto político que interpela ciertas actitudes y comportamientos, sin los cuales determinados valores relacionados con esa idea se perderían de vista. Dice relación con un sentido por la amistad civil y la solidaridad social. Pues bien, una ventaja del principio de diferencia radica en que permite concretar el pensamiento de la "fraternidad" y de esta manera volverlo realizable ${ }^{91}$.

Sin perjuicio de ello, la formulación del principio de diferencia es funcional a la realización de la libertad. Pues esta existe en el sistema completo de las libertades ciudadanas iguales. El valor de la libertad para el individuo o el grupo depende de la capacidad de lograr sus fines en ese contexto. Así, el objetivo de la justicia social radica en configurar la estructura básica de ambos principios de tal manera que el valor del sistema completo de libertades, existente para todos, sea en lo posible mayor para los menos aventajados ${ }^{22}$.

De ahí la formulación de los dos principios en los siguientes términos: primero, cada cual tiene el mismo derecho al sistema conjunto más amplio de las mismas libertades básicas, cuya realización es posible para todos. Segundo, las desigualdades sociales y económicas deben (a.) proporcionar, bajo la restricción adecuada del principio de ahorratividad, la máxima ventaja posible a los menos favorecidos y (b.) estar vinculadas a cargos y posiciones a los cuales todos pueden acceder en igualdad de oportunidades ${ }^{93}$.

\footnotetext{
89 BAYERTZ (1998) p. 37: solo puede hablarse de "solidaridad" allí donde las prestaciones de ayuda resultan de un sentimiento de unión y son voluntarias.

90 BAYERTZ (1998) pp. 38 y s.

91 RaWls (1975) pp. 126 y s.; crítico GuZmán Dalbora (2016) p. 69 con nota 14.

92 RaWls (1975) p. 233.

93 RaWls (1975) pp. 336 y s.
} 
No obstante, los dos principios de justicia siguen un orden lexical, que Rawls subraya en varias ocasiones. Este orden implica que lesiones a las libertades básicas e iguales protegidas por el primer principio no pueden justificarse o ser compensadas mediante mayores ventajas sociales o económicas ${ }^{94}$. Dicho de otra forma, el principio de diferencia supone el respeto al principio de libertad.

Ese orden relativo fluye de la premisa de la cual parte Rawls acerca de que, en lo esencial, el hombre ocupa dos posiciones: una como portador de los derechos ciudadanos igualitarios y, la otra, por su lugar en la distribución patrimonial y de los ingresos ${ }^{95}$. Según el filósofo norteamericano, entre los principios que rigen al hombre individual se distinguen dos clases de mandatos. Por un lado, las obligaciones que se reconducen a la idea de fairness y que presuponen la existencia de instituciones y costumbres. Y, por el otro, los deberes que tilda de "naturales"

Entre estos últimos, Rawls menciona los siguientes. En primer lugar, el deber de ayudar a otro cuando se encuentra en necesidad o peligro, supuesto que la ayuda sea posible sin un desmesurado peligro o daño propio. Asimismo, menciona el deber de no provocar daño ni injusto a otro. El primer deber mencionado es positivo, el segundo, en cambio, es negativo. Sin embargo, le quita explícitamente relevancia a esta última clasificación. Más importante es el contraste de estos deberes con las obligaciones de fairness. A diferencia de estas, los deberes naturales son independientes de cualquier consentimiento. No suponen necesariamente la existencia de instituciones o costumbres. Los deberes naturales valen entre los hombres de manera independiente de sus relaciones institucionales, es decir, rigen entre todos como sujetos morales iguales. En este sentido, existen no solamente frente a ciertos hombres que, por ejemplo, cooperan en una relación social determinada, sino que frente a los hombres en cuanto tales ${ }^{97}$.

Es notable que Rawls le dedique alguna reflexión a los fines de la justicia penal. Asume que, en una sociedad en cierta medida bien configurada, los que son castigados por haber infringido leyes justas normalmente han hecho algún mal. Y esto porque el fin del Derecho penal radica en la protección de los deberes naturales básicos que nos prohíben dañar a otros hombres en su cuerpo y su vida o quitarles su libertad o propiedad. No es, entonces, simplemente un sistema de impuestos y cargas que impone un precio a determinadas conductas y así pretende dirigir el comportamiento del hombre en el sentido de su ventaja recíproca. Claramente, se trata con la distribución de bienes económicos y sociales de algo completamente diferente ${ }^{98}$.

Pues bien, no es necesario suscribir la terminología iusnaturalista acuñada por Rawls para sacar provecho de las diferenciaciones que se derivan de su teoría ${ }^{99}$. Una de estas radica

\footnotetext{
94 RaWls (1975) pp. 81 y s.; preeminencia de la libertad, pp. 177, 283.

95 RaWls (1975) p. 116.

96 RAWLS (1975) pp. 133 y ss.

97 RaWls (1975) pp. 135 y s.

98 RaWls (1975) pp. 349 y s.

99 Más adelante, RaWls (1975) p. 549 nota 30, aclara en qué sentido usa el adjetivo "natural"; este alude a la diferencia entre los derechos en el sentido de la teoría de la justicia y los derechos en el sentido de la ley y la tradición; además, tales derechos se atribuyen a los hombres y tienen un peso específico; pretensiones que ceden
} 
en que el deber "natural" de ayuda a otro que se encuentra en una situación de peligro se distingue de las obligaciones de fairness, relacionadas estas con el principio de diferencia. Tal deber que Rawls tilda de "natural" se corresponde exactamente con el deber general de auxilio antes tratado -vid. supra 3.3 y 4.1. Esta diferenciación implica, a su vez, que ese deber básico se relaciona ya con el principio de libertad y no recién con el principio de diferencia.

\subsection{VALORACiÓN FinAL}

El análisis precedente, empero, no implica sostener que el deber general de auxilio ostenta el mismo status que los deberes negativos ${ }^{100}$. Asimismo, y si se parte de la premisa que los deberes positivos especiales e institucionales sí ocupan una posición equivalente a los deberes negativos, entonces el deber general de auxilio tampoco ostenta el mismo status de tales deberes positivos ${ }^{101}$.

El deber general de auxilio pertenece al principio de solidaridad y, en esa medida, se ubica en una relación asimétrica con el principio de libertad. Pero, al mismo tiempo, y en el seno del mismo principio de solidaridad, el deber general de auxilio no ocupa la misma posición que la "solidaridad social o ciudadano-estatal"102. Antes bien, tal deber general constituye un presupuesto básico de la vigencia del Estado social y de la solidaridad ciudadano-estatal.

\section{CONCLUSIONES}

En virtud de las reflexiones expuestas a lo largo del presente estudio, puede plantearse lo siguiente:

1. El Estado liberal de Derecho supone una relación asimétrica entre el principio de libertad y el principio de solidaridad.

2. Si se parte de la equivalencia entre deberes negativos y deberes positivos especiales e institucionales, entonces ambas clases de deberes constituyen manifestaciones del principio de libertad.

\footnotetext{
fácilmente frente a otros valores, no son derechos naturales; ambas características concurren en los derechos protegidos por el primer principio debido a las reglas de prioridad; la teoría de la justicia tiene las características típicas de una teoría del derecho natural.

100 Cfr. KüHL (2008) pp. 366 y ss., 373 y s.

101 De ahí que resulta confuso hablar de una "posición de garante basada en un deber de solidaridad", como lo hace VAN WEEZEL (2018) pp. 1113 y ss.

102 Si bien KüHnbach (2007) pp. 86, 138 y s., 147, reconoce el carácter doble de la solidaridad como principio interpersonal y al mismo tiempo como un asunto de la comunidad organizada en la forma del Estado, sostiene la existencia de un fundamento común tanto a la solidaridad intersubjetiva como al Estado social, pp. 196 y s., 207 y ss.; tal fundamento le lleva a concluir que existe una relación complementaria, pp. 210 y ss., e incluso sinalagmática entre solidaridad y libertad positiva, de un lado, y el deber del neaminem laedere y libertad negativa, del otro, pp. 213 ss., trasfondo sobre el cual luego no resultan comprensibles los límites de proporcionalidad impuestos a la prestación de solidaridad, pp. 216 y ss., ni por qué luego se asume no obstante la primacía de la libertad jurídica-negativa frente al principio de solidaridad, p. 221, como tampoco por qué el deber de solidaridad se restringe a la "producción y mantención de los presupuestos materiales de la libertad", p. 226.
} 
3. El deber general de auxilio así como las cargas y los deberes que dan sustento al Estado social -“solidaridad social o ciudadano-estatal”, en cambio, pertenecen al principio de solidaridad.

4. Al interior del principio de solidaridad, empero, ambas clases de deberes ocupan una posición disímil. El deber general de auxilio y la solidaridad social o ciudadanoestatal son componentes diversos del mismo principio.

\section{BIBLIOGRAFÍA}

Bayertz, Kurt (1998) "Begriff und Problem der Solidarität", Bayertz, Kurt (ed.): Solidarität, Begriff und Problem (Frankfurt a.M., Suhrkamp) pp. 11-53.

Bourgeors, Léon (1902): Solidarité (Paris, Armand Colin, $3^{\mathrm{a}}$ ed.).

Denninger, Erhard (1998): "Verfassungsrecht und Solidarität", BayerTz, Kurt (ed.), Solidarität. Begriff und Problem (Frankfurt a.M., Suhrkamp) pp. 319-344.

Depenheuer, Otto (1991-2009): Solidarität im Verfassungsstaat. Grundlegung einer normativen Theorie der Verteilung (Norderstedt, Books on demand).

GARzón VAldés, Ernesto (1986): "Los deberes positivos generales y su fundamentación”, Doxa Cuadernos de filosofía del derecho, No 3: pp. 17-33.

Guzmán Dalbora, José Luis (2016): "Acerca del valor de la fraternidad en el Derecho Penal”, Revista de Ciencias Penales, 6a época, vol. 43, No 4, pp. 65-84.

Habermas, Jürgen (1981): Theorie des kommunikativen Handelns, Tomo 2 (Frankfurt a.M., Suhrkamp).

Habermas, Jürgen (1986): "Gerechtigkeit und Solidarität", Edelstein/ Nunner-Winkler (eds.), Zur Bestimmung der Moral (Frankfurt a.M., Suhrkamp) pp. 291-318.

Habermas, Jürgen (1992): Faktizität und Geltung (Frankfurt a.M., Suhrkamp).

Harzer, Regina (1999): Die tatbestandsmässige Situation der unterlassenen Hilfeleistung ge$m \ddot{a} \beta$ \& 323 c StGB (Frankfurt a.M., Klostermann).

Hegel, G.W.F (1970): Grundlinien der Philosophie des Rechts oder Naturrecht und Staatswissenschaft im Grundrisse (Frankfurt a.M. 1970, Suhrkamp).

Hegel, G.W.F (2010): Doctrina del derecho, los deberes y la religión para el curso elemental (Buenos Aires, Biblos).

Hösle, Vittorio (1998): Hegels System. Der Idealismus der Subjektivität und das Problem der Intersubjektivität (Hamburg, Felix Meiner).

JAKOBS, Günther (1993): Strafrecht. Allgemeiner Teil (Berlin/New York, De Gruyter, 2a ed.).

KanT, Immanuel (1978): Die Metaphysik der Sitten (Frankfurt a.M., Suhrkamp, $1^{a}$ ed. 1797; $2^{\text {a }}$ ed. 1798).

KarGL, Walter (1994): "Unterlassene Hilfeleistung (§ 323c StGB). Zum Verhältnis von Recht und Moral”, Goltdammer's Archiv für Strafrecht, pp. 247-264.

KöHLER, Michael (1997): Strafrecht. AT (Berlin/Heidelberg, Springer).

KÜHL, Kristian (2008): Freiheitliche Rechtsphilosophie (Baden-Baden, Nomos).

KüHNBACH, Lena (2007): Solidaritätspflichten Unbeteiligter (Baden-Baden, Nomos).

LÉvinas, Emmanuel (1971): Totalité et infini (Paris, Livre de poche).

MARQUard, Odo (1981): Abschied vom Prinzipiellen (Stuttgart, Reclam). 
Mead, George (1973): Geist, Identität und Gesellschaft (Frankfurt a.M., Suhrkamp).

Mieth, Corina (2012): Positive Pflichten (Berlin/Boston, De Gruyter).

NAvas, Iván (2019): Deberes negativos y positivos en derecho penal (Valencia, Tirant Lo Blanch).

NovoA, Eduardo (1984): Fundamentos de los delitos de omisión (Buenos Aires, Depalma).

PAWLIK, Michael (2002): Der rechtfertigende Notstand. Zugleich ein Beitrag zum Problem strafrechtlicher Solidaritätspflichten (Berlin/New York, De Gruyter).

Pawlik, Michael (2012): Das Unrecht des Bürgers (Tübingen, Mohr).

Philipps, Lothar (1974): Der Handlungsspielraum (Frankfurt a.M., Klostermann).

Radbruch, Gustav (1967): Der Handlungsbegriff in seiner Bedeutung für das Strafrechtssystem (Darmstadt, Wissenschaftliche Buchgesellschaft).

RAWLS, John (1975): Eine Theorie der Gerechtigkeit (Frankfurt a.M., Suhrkamp).

ReNZIKOWSKI, Joachim (2013): "Solidarität in Notsituationen. Ein historischer Überblick von Thomas v. Aquin bis Hegel”, von Hirsch/ Neumann/ Seelmann (eds.), Solidarität im Strafrecht (Baden-Baden, Nomos) pp. 13-34.

Robles, Ricardo (2013): “Deberes negativos y positivos en Derecho penal”, InDret, No 4: pp. 1-21.

Samson, Eric (1971): "Begehung und Unterlassung”, Stratenwerth/ Kaufmann/ Geilen/ Hirsch/ Schreiber/ JaKobs/ Loos (eds.) Festschrift für Hans Welzel zum 70. Geburtstag (Berlin/New York, De Gruyter) pp. 578-603.

SÁnchez-Vera, Javier (1999): Pflichtdelikt und Beteiligung (Berlin, Duncker \& Humblot).

SÁnCHEZ-VERA, Javier (1999): "Estudio sobre los deberes positivos, el mandato y la figura del consenso en Derecho penal”, Cuadernos de Política criminal, No 68, 1999, pp. 347-380.

Seelmann, Kurt (1991): "Solidaritätspflichten im Strafrecht?", Jung/ Müller-Dietz/ NeuMANN (eds.), Recht und Moral (Baden-Baden, Nomos), pp. 295-304.

SeELmann, Kurt (2013): "Ideengeschichte des Solidaritätsbegriffs im Strafrecht", vON Hirsch/ Neumann/ Seelmann (eds.), Solidarität im Strafrecht (Baden-Baden, Nomos) pp. 35-47.

STEINVORTH, Ulrich (1998): “Kann Solidarität erzwingbar sein?”, BAYERTZ (ed.) Solidarität, Begriff und Problem (Frankfurt a.M., Suhrkamp) pp. 54-85.

VERMANDER, Eduard (1969): Unfallsituation und Hilfspflicht im Rahmen des $\$ 330$ c StGB, (Tübingen, Mohr).

van Weezel, Alex (2019): "Optimización de la autonomía y deberes penales de solidaridad”, Política Criminal, vol. 13, No 26: pp. 1074-1139.

Wilenmann, Javier (2014): Freiheitsdistribution und Verantwortungsbegriff (Tübingen, Mohr). 